\title{
Formulating and Implementing Socioeconomic Policies for Children in the Context of HIV/AIDS: A South African Case Study
}

\author{
Debbie Budlender, Paula Proudlock and Lucy Jamieson
}

\begin{abstract}
1 Background
The HIV prevalence rate in South Africa is among the highest in the world and the country also outranks all others in the absolute number of infected people within its borders. HIV/AIDS is among the major problems facing the country, but certainly not the only major socioeconomic challenge. Although South Africa is a middle-income country, it has high levels of poverty due to highly unequal distribution of income and resources.
\end{abstract}

\begin{abstract}
This article examines how policies in relation to financial and other care for children have been formulated since the mid-1990s in this situation. It draws heavily on the personal experience and knowledge of the three authors, who played a range of roles in the development of and advocacy around the three policies listed below. It also draws on a range of other studies in some of the policy areas, as well as the official laws, regulations and policy papers.

For the purposes of this article, the term 'policy' is understood in a broad sense that extends to laws and regulations. The article focuses on issues relating to both the content of the policies, and the process through which they were developed, as well as how process and content influenced each other.
\end{abstract}

This study discusses three policies: (1) the Child Support Grant (CSG), (2) the Children's Act and Amendment Bill, and (3) the Foster Care Grant (FCG). The policies differ widely in terms of the stage of the policy process, as well as the way in which the policy has been, or is being, developed. ${ }^{1}$ What is common across the three policies is that they are large-scale interventions involving significant amounts of money, and they were not designed specifically to address HIV/AIDS-related issues.

The South African government's ambivalent stance on HIV/AIDS is well known (Gumede 2005), but has varied across departments and affected the policies examined in this article less than policy and practice directly targeting HIV/AIDS. The strongest denialism came from the Minister and Department of Health and the Presidency. In contrast, the Minister and Department of Social Development have been among the most open about acknowledging the pandemic and discussing how to address it. The Department of Social Development is weaker than many other departments in terms of status and capacity. Ironically, the low importance accorded to social welfare by many of the key decision-makers might have allowed more space for the development of innovative policy.

In the mid-1990s, soon after the formal transition from apartheid to a democratic government, the Social Welfare White Paper introduced the notion of 'developmental social welfare'. The new approach promoted interventions at a broad level so as to try to prevent problems arising in the first place, rather than simply addressing individual problems as they arose. The new policy approach is relevant for all three of the policies studied. In respect of the Children's Act, the new approach supported the emphasis on prevention 
and early intervention, rather than on simply helping those already in trouble. In respect of the two grants, the new approach was interpreted by some as implying that grants were an inferior form of assistance. Grants were (incorrectly) seen as 'handouts' or 'band-aid'. However, some researchers (Posel et al. 2006; Samson et al. 2004) have argued that grants provide people with the means to help themselves and can promote economic engagement.

The FCG existed during the apartheid years. The other two policies - the CSG and Children's Act (which was to replace the existing Child Care Act) were developed against the background of a new Constitution which provides justiciable socioeconomic rights, with especially strong rights for children. Public interest litigation through the courts has been used as one way of influencing policy.

The government has sought to balance the push towards rights-based public policies and its desire for 'fiscal prudence'. The grants are of special interest in discussions around finances, as once the right to a grant has been established in a national law, a government has an ongoing obligation to provide the necessary funds and any non-provision can be challenged as unconstitutional. In the debates around the CSG and the Children's Bill, in particular, many of the arguments against extending provision were based on whether the state is constitutionally obliged to deliver the relevant service, the cost involved, and the risk of litigation if resource and capacity constraints prevent the state from being able to deliver on the promised benefit or service. Today the threat of court action is in the minds of both the executive and the legislature when developing policies and implementing them.

Children can be expected to have much less 'voice' than adults to influence policy, therefore child rights activists within government and non-governmental organisations (NGOs) have a critical role to play in shaping policy. The three case studies provide interesting contrasts in terms of both the depth of consultation and public participation, as well as the stage at which it occurs. There are also differences as to who is involved in terms of civil society and the legislatures.

There is also a range of issues related to the institutional set-up in South Africa post-1994 that influenced the process and content of policymaking
Constitutionally, national government bears the main responsibility for social policy, while provinces bear the main responsibility for implementation. The allocation of functions affects implementation and equity as the nine provinces differ considerably in respect of capacity and resources, among others. These differences are largely a legacy of the apartheid era. Stated crudely, the areas which previously incorporated homelands continue to be under-served, less wealthy and have less 'efficient' administration. Somewhat paradoxically, grants were among the more efficiently administered services in these areas, and the CSG was able to build on this existing extensive delivery system.

\section{Child support grant}

The Child Support Grant (CSG) is a relatively new grant, introduced during the late 1990s. It replaced the previous State Maintenance Grant (SMG). In 1998, the SMG reached approximately 300,000 children, of whom a small minority were from the poorest African population group. In the mid-1990s, approximately R1.2 billion was allocated for the SMG in the government budget but the new government estimated that it would cost around R12 billion per year to extend the grant to all groups under the existing rules. This was equivalent to the annual health budget. The provincial and national ministers responsible were therefore on the verge of agreeing that the SMG should be abolished. However, after intervention by a civil society expert on welfare a committee was established to assess the existing system of support to children and families, and recommend alternative approaches keeping within the current budget.

The committee was given only six months in which to report and could not engage in a full consultation process. The committee did, however, commission several pieces of research to inform its discussions. It also visited provincial departments and NGOs, as well as national agencies, to inform them about the committee's work, gather information from them, and inform those in the provinces of their right to demand public hearings.

The committee's final report was submitted to the government in August 1996. The committee proposed that the SMG should be phased out and the new CSG introduced at R70 per child per month up to the age of seven. In February 1997, the Cabinet accepted most of the proposals. 
At this stage of the process, civil society organisations convened a meeting to discuss the proposals. As a result of their lobbying, the parliamentary committee on welfare held public hearings attended by the Minister of Welfare, where several organisations from civil society made submissions. After further advocacy, in July 1997, the National Executive Council (NEC) of the African National Congress (ANC) took a formal decision that the amount should be R100/month rather than the R70 previously proposed. Civil society pressure almost certainly was a key factor in this decision, and the CSG was introduced in 1998 at R100/month.

The CSG involved a major reconceptualisation of many aspects of the SMG. Perhaps most important, the CSG is not targeted only at mothers (and fathers) nor only at those who have lost spouses. Instead it is intended to 'follow the child' and be available to whoever is the primary caregiver for any child living in poverty.

The SMG had been intended for a society in which children were born into a family consisting of an employed father, a non-employed mother responsible for the care of the children, and one or two children. With this family profile, a grant was seen to be necessary when the father was unavailable and income thus depleted. The reconceptualised grant is more appropriate for a society such as South Africa, with a family structure that is very diverse and fractured (in part, as a result of apartheid). In particular, it caters better for a situation where large numbers of women bear children outside permanent partnerships; where many men neglect their responsibilities towards the children they have fathered; and where care by extended family members is common. The 'follow-the-child' aspect is also appropriate for a society with high HIV prevalence, in which there will also be large numbers of orphans. By 2007, there were an estimated 1,708,032 maternal orphans in the country, of whom 1,201,675 were orphaned as a result of AIDS?

The CSG has undergone important changes since its introduction in the late 1990s. These include removal of some conditions such as the applicant making herself available for participation in development programmes, changes to the means test, increases to the amount of the grant and extension of the age group covered. Many of the changes were, in part, the result of advocacy by civil society organisations. In the early years the changes - all of which made the grant more accessible - were also motivated by the slow initial take-up. The government was thus open to introducing changes that could increase take-up and allay some of the criticisms.

Since the establishment of the grant, civil society organisations have maintained an interesting balance between assisting government in some tasks associated with the grant and adopting strong advocacy positions against government on other aspects. Over time, the CSG has become widely accepted by civil society organisations, to the extent that many service providers see one of their service delivery tasks as helping people to access the grant. Nevertheless, the grant is still not seen as optimal. Thus at the same time as helping people to get the grant, many civil society organisations are advocating for it to be improved.

Overall, the grant is acknowledged to be successful. Advantages of the grant over many alternative poverty alleviation measures are the small overhead costs compared with more labour- and facilityintensive services, and the limited administration involved. There is also a growing body of research evidence available on the impact of the CSG (Kola et al. 2000; Samson et al. 2004; Budlender and Woolard 2006; Agüero et al. 2005; Case et al. 2005) Among the findings are that the grant improves the ability of caregivers to care for the child and buy necessities for them; that it results in increases of height-for-age, an important proxy for child wellbeing; and that it increases the already high level of school enrolment both for the immediate child beneficiary and other children in the household.

In recent years, there has been some discussion, prompted by international 'fashions', as to whether conditionality should be introduced in respect of the CSG. However, without conditionality, the grant has proved to be effective in terms of promoting health and education. An education-related conditionality would also make little sense given the already high enrolment rates in the country and research evidence that grant receipt is associated with an increase in the already high rate (Budlender and Woolard 2006). The danger of introducing conditionality is that it might well prevent those who are most in need from accessing the grant because their disadvantage prevents them and their caregivers from fulfilling the conditions. 


\section{Children's Act and Amendment Bill}

The Children's Act was passed in 2005 while the Children's Amendment Bill was, at the time of writing, still to be enacted. The two measures are closely related, with the first covering functions for which national government is responsible, while the second deals with provincial responsibilities, thus necessitating a more complicated process.

The purpose of the Children's Act and the Children's Amendment Bill is to give effect to the Constitutional rights of children to:

- Family care, parental care or appropriate alternative care

- Social services

- Protection from abuse, neglect, maltreatment and degradation

These issues have particular salience in the context of a severe HIV/AIDS pandemic. For example, social services can play a critical role in providing care and protection for the large numbers of children who lose their caregivers as a result of the pandemic. The measures also emphasise the core international and constitutional principle that, in every matter affecting a child, the child's best interests should be of paramount importance. This is an important development because the 1983 Child Care Act, which was written by the apartheid government, does not reflect a child rights perspective and does not take into account equality for all children in social welfare service provision.

The Children's Amendment Bill provides for and regulates the following social services for children and their families:

- Partial care (crèches)

- Early childhood development (ECD) centres and programmes

- Prevention and early intervention programmes (to assist families in preventing abuse and neglect from occurring)

- Protection services for children who have been abused and neglected

- A mentorship scheme for child-headed households

- Foster care

- Child and youth care centres (children's homes, places of safety, secure care facilities, schools of industry, reform schools, and shelters for street children)

- Drop-in centres for vulnerable children.
These services are currently provided by both government and non-profit organisations. The level of service delivery is way below the need and massive upscaling will be required over the next few years.

The Children's Bill has taken a very long time to develop, in marked contrast to the CSG. Factors responsible for this include: the length and scope of the bill; four changes in leadership of the executive drafting team; the fact that the bill prescribes activities for a range of different government departments and spheres (levels) of government; the inclusive consultative and participatory process followed; and the splitting of the legislation into two bills. While the participatory nature of the process may have added to the length of the process, the high levels of participation and the public pressure this has generated have also had the effect of ensuring that the process was not neglected or subject to long periods of inactivity.

From late 2002 onwards, the policy development process was accompanied by a concerted civil society advocacy campaign. From the start, the relatively large number of organisations with an interest in various aspects of the bill realised that they did not have the time, energy, resources or skills necessary to engage in successful law reform advocacy on their own. They also recognised that having a unified voice would increase the chances of winning concessions. The Children's Institute, a research and advocacy unit based at the University of Cape Town, applied for, and was awarded, funding to coordinate a campaign and in March 2003 a total of 35 organisations joined the Children's Bill Working Group. The working group was later expanded by the recruitment of ten new members from the umbrella organisations in order to broaden representivity.

The aims of the working group included, among others, promoting the use of evidence in the decision-making process. More generally, the methodology was built around research, consultation, and dialogue with organisations on the ground. While the importance of a unified voice was promoted, the working group was divided into subgroups so that everyone could contribute to the area in which they had appropriate experience, knowledge and interest. Regular workshops were held in order to share evidence, debate and reach common understandings about the best way forward. 
Throughout the deliberations the working group and its allies used a wide range of different advocacy initiatives. Initiatives included written submissions, presentations at public hearings, workshops, meeting with members of the provincial and national legislatures on constituency visits, study visits or in the legislature, and taking MPs on site visits to see service challenges first hand.

While Parliament has been the main focus of the campaign's work, it is not the only one. working group members also met at key points with departmental representatives to hear their views, keep them informed of civil society initiatives, and debate the various clauses. The legislatures rely heavily on the executive drafting team's legal and service delivery expertise when they are uncertain. Ensuring that the executive team was fully briefed on the working group's evidence and positions facilitated greater understanding and acceptance by the executive of the Group's recommendations. This, in turn, facilitated Parliament's understanding.

The Children's Act has a range of provisions of special relevance to HIV/AIDS. For example, the Act does not assume that all children are cared for by parents or legal guardians, thus it caters for orphaned children, many of whom are cared for by relatives in informal care relationships. The definition of caregiver was expanded to give responsibilities and rights to anyone who de facto cares for children, including relatives looking after children and staff in residential facilities. In addition, the Act changes the way children can consent to medical treatment, surgical operations, HIV testing and disclosure of results, and access to contraception.

Children in child-headed households were added to the list of children who may be in need of care and protection. The Children's Amendment Bill also provides for a mentorship scheme to support childheaded households. The definition of child-headed households includes children living alone because they have been orphaned or abandoned. It also includes households where the adult is terminally ill and a child has taken on the responsibility of caring for the adult as well as the other children in the household. Parliament shared the public's concerns that children heading households were taking on responsibilities usually shouldered by adults. However, they agreed these households should be legally recognised and supported with services.
Finances and resourcing have arisen repeatedly as a topic in the discussions around the Children's Bill. $A$ first round of advocacy around funding obligations resulted in an amendment to s4(2) of the first Bill which provided that: 'recognizing that competing social and economic needs exist, the State must, in the implementation of this Act, take reasonable measures within its available resources to achieve the progressive realization of the objects of this Act'. After submissions from the Children's Institute and Human Rights Commission, the word 'progressive' was removed and the words 'maximum extent' were inserted before 'available resources'. This means that the National Treasury and the provinces are obliged to prioritise the implementation of the Children's Act when making decisions about budgets and the allocation of resources. $A$ later amendment changed the words 'may provide' to 'must provide' in respect of a range of services falling under provincial government.

\section{Foster care grant}

In most countries with developed child welfare services, foster care is the first of a two-step process in ensuring care for children whose own parents cannot care for them. Foster care is temporary and is followed by permanent full adoption, which is often accompanied by financial support from the state. In South Africa, in contrast, legal adoption is not accompanied by financial support, and fostering which is accompanied by a grant - often becomes permanent.

The Foster Care Grant (FCG) has been in existence for many decades. Its original intention was to provide financial assistance to non-relatives who took on responsibility for the care of a child in need of alternative care as a result either of insufficient care (e.g. from neglect, abuse, abandonment or being orphaned) or as a result of child behavioural difficulties. The Department of Social Development's Guidelines in respect of the Child Care Act make clear that placements were intended to be temporary, with the hope that the child would return to the care of his or her biological parent(s). This is obviously not possible in the case of children who have been orphaned. The grant has, however, been used increasingly to provide long-term financial assistance to those who take on the care of children orphaned by AIDS, whereas previously it was not given to close relatives. In effect, the grant has increasingly been used as a poverty alleviation measure rather than as a child protection measure (Meintjes et al. 2003). The attraction - for 
applicants, social workers and others - of using the grant in this way is obvious given the gap between the amount of the FCG and that of the CSG - R620 vs. R200 per child in 2007.

The legal process of applying for a foster care placement is complicated, lengthy and timeconsuming. Social workers play a central role in this process and the current severe shortage of this category of workers means that the delays in the foster care process are even greater than would otherwise be the case. The pressure is increased by the fact that each foster care placement must be ordered by the Court and then reviewed by a social worker on a biannual basis.

There has been no formal and explicit policy change in respect of the FCG in recent years, although the new Children's Act and Children's Amendment Bill will usher in some critical changes in the future. However, the marked shift described above in how the FCG is used has contributed to a substantial increase in take-up, and resulting backlogs in processing applications. $A$ large proportion of current foster care placements involve care by relatives of children orphaned by AIDS. This use of the foster care system and grants for children orphaned by AIDS has been openly encouraged by government actors, including the Minister of Social Development.

The large increase in the number of foster care applications has overwhelmed the provincial Departments of Social Development and, in particular, the social workers who are involved in children's services. The burden of processing increasing numbers of foster care applications has made provision of other meaningful professional services impossible.

Members of the parliamentary committee struggled to find a solution to these challenges during their deliberations on the relevant parts of the Children's Bill. MPs recognised the need for major reform, but were reluctant to introduce changes that would necessitate changes to the Social Assistance Act as this Act was not on the table for discussion at the time.

From the side of civil society, in 2003, the Children's Institute added a detailed research paper (Meintjes et al. 2003) to the debate. The paper was intended to question the logic, ethics and cost-efficiency of the use of the FCG as a poverty alleviation mechanism for orphans. It also questioned, with the support of both quantitative and ethnographic data, the idea that care by adult relatives other than parents could be regarded as atypical or 'alternative'.

Initially, there was very little consensus among working group members, some of whom found the Institute's position too crude. Some members were also uncomfortable with supporting a call for orphans to receive the CSG when the FCG amount was substantially higher and the CSG was restricted to children under 14. Those who supported the Children's Institute's approach felt it was inequitable to provide higher amounts for orphans when many non-orphans lived in similar, or worse, conditions of poverty.

Through discussion, meetings and workshops, the positions of working group members moved closer to each other. The general consensus at the time of writing is that the Act should provide for some sort of informal kinship care that does not require a court-based process and that is distinct from foster care. The foster care system should be used for its original purpose, namely assistance to children legally 'in need of care and protection'. There is consensus that the level of the CSG also needs to be increased compared with the FCG and extended to age 18. Without the latter change, strong incentives will remain for both social workers and caregivers to use the foster care system to access the FCG.

In the end, Parliament made significant changes to the Children's Amendment Bill, which broadened foster care well beyond the original concept. In essence, the portfolio committee confirmed the Minister's spoken policy and made it clear in law for the first time that 'family members' qualify to be foster parents. With the Minister and now Parliament making it clear that the FCG is the preferred policy option for relatives caring for orphans, a change is unlikely to occur. When the age covered and amount of the CSG are increased, the debate could possibly be revived.

\section{Discussion}

\subsection{Constitutional obligations}

South Africa has a particularly strong Constitution, especially in the area of socioeconomic rights, and even more particularly in respect of children. The policy development described in this article has thus often been framed in terms of constitutional rights and duties. Civil society is a strong advocate for a 
rights-based approach being followed in the policy development process and this comes out clearly in their advocacy campaigns in respect of all three policies. The executive and Parliament have become wise to this after a series of successful Constitutional challenges. The fear of the litigation that could arise should government not deliver has made government more cautious when passing legislation.

\subsection{The perceived fiscal envelope}

The case studies raise the question of the weight that should be attached in the decision-making process to the financial implications of the various policy options on the table. For purposes of good planning, it is essential that all policy options should be costed and that the cost of the reform should be considered as one of the factors in the decision-making process. Given the relative strength of the South African economy it should, however, not be the main factor. The case studies suggest that the financial question is likely to be emphasised when government does not want to do something. However, if government itself is fully behind a reform or is persuaded to make a reform by dialogue with or pressure from civil society, financial implications become peripheral.

\subsection{Human resources}

Budgetary analysis in relation to the Children's Bill (Budlender et al. 2008) reveals the large gap between policy and the budget needed to implement it. However, even if the money were to be allocated, this would not solve the problem. Because of the heavy emphasis on services in this policy, there is a large-scale need for trained personnel to deliver them. One problem has been the requirement that some services only be provided by highly trained workers, such as social workers. This problem has been partially addressed by relaxing this condition in respect of some services and requiring instead that a 'social service professional' deliver the service. These workers too are in short supply. There are also still far from sufficient social workers to deliver the services now reserved for them.

The human resource problem has a financial angle in terms of the low pay received by those who deliver the services. Unless the low pay issue is addressed, there will continue to be grave shortages of these workers, and those who are in place will tend to feel overburdened, resentful and angry. As a result, their services will often not be of as good a quality as they should be.

\subsection{Public participation}

In respect of the CSG, the technical committee which developed the policy was set up in a way that did not provide for significant public participation. While Parliament debated and passed the Bill that introduced the CSG and provided a space for civil society to be heard, it played a very small role in actually shaping the policy. In contrast, the Children's Bill/Act process has seen substantial public participation during the technical committee, executive and parliamentary phases, and has also involved active engagement of the legislatures over a long period. In respect of the shift in use of the FCG there was initially no consultation. The Children's Bill process provided the opportunity for the policy shift to be discussed, but a sensible decision is difficult without changes in the other grants and these grants fall under separate legislation.

For the Children's Bill, civil society came together at an early stage in an attempt to speak with one voice. Significant effort was put into maintaining this alliance, and into reaching common positions where these did not initially exist. Significant effort and resources were required to achieve this over the large number of topics covered by the Bill.

\subsection{The impact of the HIV/AIDS lobby}

The three case studies cover mainstream policies which have an enormous impact on children affected by HIV/AIDS and their families. The fact that they were not conceived specifically as policies to combat the effects of the HIV/AIDS pandemic and that their target goes beyond orphans meant that the HIV sector did not focus their energy on the campaigns. During the Children's Bill law reform process, both committees in Parliament and the Department of Social Development were sympathetic to the problem of orphans and other children affected by HIV/AIDS and whenever the HIV lobby engaged with the process, they were successful. However, parallel policy development processes for 'orphaned and vulnerable children' tended to divert the HIV sector within civil society from concentrating on the Children's Bill campaign, despite the fact that the services being provided and regulated in the Bill would form the bulk of services to be delivered to orphaned and vulnerable children.

Some of the issues were taken up by other subgroups For example, the disability sector campaigned for the insertion of a clause dedicated to the rights of children with disabilities and chronic illnesses. 
However, there is little doubt that the failure of the HIV sector to unite behind a single solution with regard to the foster care problem, resulted in a weak campaign and what we are left with is a compromise.

The role of the international and donor community in calling for targeted interventions for 'orphans and vulnerable children' tends to reinforce the diversion of both government and civil society attention from larger, mainstream policy processes that ultimately could have a greater impact on improving the lives of children infected and affected by HIV/AIDS.

\subsection{The locus of decision-making}

The article reveals a range of government-related actors and institutions playing a part in the policymaking process. It is, however, difficult to pinpoint a single place where the 'real' decision is taken. In reality, what happens in one forum will influence decisions in another forum. Further, there is an overlap of actors between forums. Rather than a single decision-making point, then, it seems more likely that options are discussed until there seems to be enough 'buy-in' across a number of forums. The fact that South African politics is heavily dominated by a single party, the ANC, facilitates such cross-influences.

\subsection{Targeting}

Some would argue that all children in a society such as South Africa are affected by HIV/AIDS in some way. This generalisation is not particularly helpful, as some children are clearly affected more than others. In particular, those who are orphaned, those who are themselves infected, and those whose caregivers are infected are especially affected. However, recognition of the special needs of children affected by HIV/AIDS does not remove their simultaneous need to access mainstream programmes such as water, healthcare services, social welfare services and social assistance. The concentration on targeting can divert attention from the need to mainstream the needs of children affected by HIV/AIDS, in the sense of addressing their needs in general measures and ensuring that their needs which are not specific to HIV/AIDS are also addressed.

The arguments against targeting might be less strong in a country (a) in which the pandemic is less widespread and where it might therefore be easier to focus on a limited number of children with particular needs, or (b) where resources are more constrained and it is therefore financially more difficult to make services available for all.

\section{Conclusion}

\subsection{Evidence-based policymaking}

The Joint Learning Initiative on Children and HIV/AIDS (JLICA) is intended to promote evidencebased policymaking. The ability to engage in evidence-based policymaking in South Africa has increased significantly over the years covered by this article. In the mid-1990s there were few reliable statistics available. By the mid-2000s data availability and quality were much improved, although far from perfect. The case studies illustrate how available statistical and budget data were used in the advocacy campaigns. In addition, the campaigns often relied on the use of case studies and descriptions of real life experiences from practitioners or service users. These were especially useful when presented alongside professional research as they helped decision-makers to understand complex evidence.

The major question facing the JLICA initiative is how best to meet the needs of children in the context of an HIV/AIDS pandemic, and how the particular context of policymaking influences what can be and is done. The case studies presented above describe the debates and interventions that have occurred in South Africa in this respect. The article suggests that in this country, where children are adversely affected by many factors, the mainstream approach seems preferable to a targeted one in respect of poverty alleviation and social services outside of health.

The article has described how the policy process has encompassed a mixture of activism, advocacy and policy dialogue on the part of civil society as well as, where necessary, the use of litigation. The three policy stories illustrate the importance of advocacy continuing long after the decision is taken to implement a new policy. Ongoing vigilance is needed during implementation to ensure that the envisaged benefits of a policy are realised and that problems that emerge during implementation are addressed. 


\section{Notes}

1 The article was written before the Children's Amendment Bill was signed by the President in March 2008. At the time of writing this summary article, the Bill has become the Children's Amendment Act No. 41 of 2007, but the content

\section{References}

Agüero, J.M.; Carter, M.R. and Woolard, I. (2005) From Flows to Stocks: The Impact of Unconditional Cash Transfers on Human Capital, November, unpublished manuscript

Budlender, D. and Woolard, I. (2006) The Impact of the South African Child Support and Old Age Grants on Children's Schooling and Work, Geneva: International Labour Organization (ILO)

Budlender, D.; Proudlock, P. and Monson, J. (2008) 'Budget Allocations for Implementing the Children's Act', in P. Proudlock, M. Dutschke, L. Jamieson, J. Monson and C. Smith (eds), South African Child Gauge 2007/2008, Cape Town: Children's Institute, University of Cape Town Case, A.; Hosegood, V. and Lund, F. (2005) 'The Reach and Impact of Child Support Grants: Evidence from KwaZulu-Natal', Development Southern Africa 22.4: 467-82

Gumede, W.M. (2005) Thabo Mbeki and the Battle for the Soul of the AN, Cape Town: Zebra Press

Kola, S.; Braehmer, S.; Kanyane, M.; Morake, R. and Kimmie, Z. (2000) Phasing in the Child Support remains the same as at the time the original article was written.

2 Estimates based on the AIDS and Demographic model of the Actuarial Society of South Africa (www.actuarialsociety.org.za).

Grant: A Social Impact Study, Johannesburg: Community Agency for Social Enquiry

Meintjes, H.; Budlender, D.; Giese, S. and Johnson, L. (2003) Children 'in Need of Care' or in Need of Cash?: Questioning Social Security Provisions for Orphans in the Context of the South African AIDS Pandemic, Joint Working Paper, Cape Town: Children's Institute and Centre for Actuarial Research, University of Cape Town

Posel, D.; Fairburn, J. and Lund, F. (2006) 'Labour Migration and Households: $A$ Reconsideration of the Effects of the Social Pension on Labour Supply in South Africa', Economic Modelling 23.5: 836-53

Samson, M.L.; Ndlebe, U.; MacQuene, A.; van Niekerk, K.; Ghandi, I.; Harigaya, V.T. and Abrahams, C. (2004) The Social and Economic Impact of South Africa's Social Security System, Cape Town: Department of Social Development, Economic Policy Research Institute 